\title{
THE COLLEGE'S COMMENTS ON THE REPORT OF THE ROYAL COMMISSION ON GAMBLING*
}

Summary

The Royal College of Psychiatrists is concerned that the importance of pathological gambling, a condition associated with a great deal of individual distress and social disturbance, was largely dismissed by the Royal Commission on Gambling. While we agree that more hard data regarding gambling in general and pathological gambling in particular would be valuable (Section 2), there is already sufficient evidence to show that public policy on gambling has an important effect on the incidence of pathological gambling. In particular, it should be recognized that the total amount of gambling occurring in the community determines the level of pathological gambling. Consequently, although prohibition is neither desirable nor practicable, the more gambling is encouraged the more likely are some people to misuse it (Section 3).

This situation is compounded by incitement to excessive gambling which occurs especially in betting offices to increase the levy, with instant lotteries to provide additional funds for societies and local authorities, and in the use of jackpot machines to subsidize bingo clubs (Sections 5, 6, 7, 9).

Furthermore, it is regrettable that the Royal Commission's preoccupation with the mathematical odds and financial aspects of gambling resulted in important psychological factors being disregarded. While it is wholly desirable that gamblers should be given an economic fair deal, this is by no means the end of consumer protection (Section 4).

It is therefore important that the total situation should be carefully monitored, and this can only be adequately performed by a Gambling Authority (Section 8).

"(HMSO, 1978, Cmnd 7200). The College's Evidence to the Royal Commission in News and Noles for May 1977, pp 4-12.

\section{PSYCHOTHERAPY SECTION}

The following are details of the next four Open Meetings :

Wednesday, 14 March, at 8.15 p.m.

Dr Ismond Rosen Perversion as a Regulator of Self Esteem

Wednesday, 11 April, at 8.15 p.m.

Professor Salvador

Minuchen

A Demonstration

Professor Minuchen is Professor of Clinical Psychiatry at the University of Pennsylvania, and Director of
Training, Family Therapy Training Centre, Philadelphia Child Guidance Clinic.

Wednesday, 9 May, at 8.15 p.m.

Dr William Gillespie Relationship between Psycho-Analysis and Hypnosis

Wednesday, 13 June, at 8.15 p.m.

Dr Arnon Bentovim and

Dr Warren Kinston Title to be announced

All these meetings will take place at the Tavistock Centre, 120 Belsize Lane, London NW3.

\section{WORKSHOP IN RESEARCH METHODS FOR PSYCHIATRY}

The University of Birmingham and the Research Committee of the College are planning an intensive residential course to deal with practical aspects of carrying out psychiatric research. It is envisaged that this will be particularly appropriate for psychiatrists in training, but others will not be excluded. There will be discussion papers and small group seminars dealing with specific research problems. It is hoped that this workshop will act as a stimulus to initiate research.

The course will take place from 21-24 May at Stowe House, Lichfield, and the number of participants will be limited. Enquiries should be addressed to $\operatorname{Dr} \mathrm{A}$. C. P. Sims, Department of Psychiatry, Queen Elizabeth Hospital, Birmingham B15 2TH. 